\title{
Trabalho infantil: uma discussão sobre direitos, causas e consequências
}

\author{
Cicero Charlison Renan Alves ${ }^{1}$; Lais Almeida de Sousa ${ }^{2}$; Virginia Ellen Varela Clementino ${ }^{3}$; Jessé Gomes Ferreira ${ }^{4}$
}

\begin{abstract}
Resumo: Este trabalho versa sobre a exploração do trabalho infantil, assim como suas causas e consequências na vida de crianças e adolescentes, que na maioria das vezes vivem em um ambiente social vulnerável, pois a pobreza é uma das principais causas para que ocorra esse tipo de problemática. Sabe-se que essa situação acarreta seqüelas em suas vidas, pois, em geral, os mesmos tendem a deixarem os estudos precocemente, não desfrutam da infância, já que seu tempo está voltado para o trabalho, o que, mais adiante, não irá favorecer o seu desenvolvimento. Para avaliar tal problemática utilizamos como técnica metodológica a revisão bibliográfica. Observou-se também neste estudo, o papel da família, bem como o papel Estado no sentido de combater e erradicar tal problemática. Os resultados levaram a crer que é necessário um amplo processo de discussão com a participação da sociedade, no sentido de uma reestruturação de políticas sociais públicas, que sejam mais eficazes, na geração de emprego, melhoria da educação e da assistência a essa faixa da população.
\end{abstract}

Palavras Chaves: Exploração, Pobreza, Questão Social, Trabalho infantil.

\section{Child labor: a discussion of rights, causes and consequences}

\begin{abstract}
This article focuses on the exploitation of child labor, as well as its causes and consequences in the lives of children and adolescents, who mostly live in a social environment vulnerable, because poverty is a major cause to occur such of problematic. It is known that thissituation causes sequels in their lives, because in general, they tend to leave school early, do not enjoy childhood since his time is focused on the job, which, later, will not encourage their development. To evaluate this issue as a methodological technique used the literature review. It was also observed in this study, the role of the family as well as the role of the State to combat and eradicate thisproblem. The results led to believe that it takes a extensive process of discussion with the participation of society, in the sense of arestructuring of public social policies that are more effective in creating jobs, improving education and assistance to this population .
\end{abstract}

Key Words: Exploration, Poverty, Social Issues, Child Labor.

\footnotetext{
${ }^{1}$ Professor da Faculdade Vale do Salgado - FVS. Graduado Em Serviço Social pela Faculdade Leão Sampaio - FLS, Especialista em Direito constitucional e administrativo, Residente em Saúde Coletiva pela Escola de Saúde Pública - ESP do Ceará. Mestrando em Ciências da Saúde pela FMABC - Faculdade de Medicina do ABC Paulista. Email: onciole_alves@ hotmail.com

${ }^{2}$ Professor da Faculdade Vale do Salgado - FVS, especialista em Serviço Social pela Faculdade Leão Sampaio e professora do departamento de Serviço Social da Faculdade Vale do Salgado Icó Ceará. laisis_almeida@yahoo.com.br

3 Assistente Social do município de Várzea Alegre, especialista em Serviço Social pela Faculdade Leão Sampaio. E_mail: wirginiavarela@yahoo.com.br

${ }^{4}$ Professor da Faculdade Vale do Salgado - FVS. Graduado em Ciências Econômicas pela Universidade Regional do Cariri - URCA.

Especialista em Gestão de Políticas Públicas pela FVS. Contato: jesse_economia@yahoo.com.br
} 


\section{Introdução}

Ao realizarmos um estudo sobre as causas e conseqüências da exploração do trabalho infantil, buscou-se textos, dados quantitativos e porcentagens acerca dessa problemática, portanto é visto que no nosso estado (Ceará) encontra-se em $15^{\circ}$ lugar com índice de trabalho infantil. De acordo com o Ministério do Trabalho cerca de 58 mil crianças trabalham no Ceará, já com base no censo 2010 do Instituto Brasileiro de Geografia e Estatística (IBGE), de um total de 847.465 crianças cearenses, 58.825 entre 10 e 14 anos de idade trabalham, visto que na atualidade com as políticas públicas que envolvem a criança e o adolescente, esse número continua sendo muito alarmante.

Buscamos identificar o que é trabalho infantil, contudo certificamos que em nosso país qualquer trabalho exercido por crianças e adolescentes com menos de 16 anos idade é crime, salvo em condição de aprendiz a partir dos 14 anos de idade.

Algumas atividades foram identificadas com mais frequiência como trabalho infantil: trabalhar na casa de famílias como doméstica ou babá, em restaurantes, vender bala no sinal, trabalhos rurais e em comércio. Portanto, quando a criança e o adolescente deixam de freqüentar a escola, brincar, isso significa trabalho infantil.

O objetivo deste artigo é analisar as causas e consequências que o trabalho informal acarreta a crianças e adolescentes, perceber o papel da família nessa expressão da questão social.

Sabe-se que a pobreza e o incentivo das famílias que não tem renda fixa são fortes fatores para que menores de idade deixem de serem crianças e passem a viver uma vida sofrida de sacrifícios, para o sustento mínimo de suas famílias, com isso a mesma sem condições financeiras de garantir as necessidades básicas, a criança é convidada a ir ao "submundo do trabalho", em um contexto de mão de obra barata, privando-a da infância. Hoje no Brasil, a exploração infantil esta presente em diversos ambientes, crianças são encontradas executando atividades ilegais, como a exploração sexual e o trafico de drogas

\section{Contextualizando o processo histórico do trabalho infantil}

Sabe-se que na idade média tinha-se uma naturalização do trabalho infantil, pois nessa época a infância não era vista como uma etapa de desenvolvimento humano, e sim apenas um instrumento de trabalho barato. Quando as crianças já tinham um crescimento físico, mais ou menos com 6 ou 7 anos 
de idade, já eram possibilitados a fazer atividades, eram logo postos a trabalhar e até a vestir-se e ter comportamento de um adulto, mas isso só ocorria com os filhos dos camponeses, pois eram as famílias de baixa renda da época.

Porém, com o processo de industrialização e com a instalação do capitalismo, tem-se o agravamento das expressões da questão social ${ }^{1}$, das desigualdades sociais, a qual a sociedade divide-se em duas classes sociais: burguesia e proletariado, onde uma apropria-se de outra, sendo que a primeira é a dona dos meios de produção e exploração a segunda, que por seguinte vende sua mão-de-obra para a burguesia. Com essa Revolução Industrial cresce os meios de produção facilitando a obtenção do lucro pela classe dominante (burguesia).

Com isso tem-se a migração nas cidades, chamada de êxodo rural. As pessoas do meio rural vão para o meio urbano, com o objetivo de melhorar as condições de vida. Os trabalhadores vendem sua força de trabalho por um salário mínimo para suprir suas necessidades básicas, com isso toda a família tinha que trabalhar para ajudar no sustento de todos, e até crianças foram postas para trabalhar, ganhando bem menos que os homens adultos. Mas para o capitalismo essa forma de agir com a infância era um meio de "educá-los", pois assim eles estariam longe da criminalidade, da rebeldia, das doenças de rua. Mas o que o sistema queria e que até hoje busca é o lucro, e ainda mais sua expansão.

Segundo Marx (1968.p. 449) no capitulo 1 volume 2 descreve que:

[...] de poderosos meio de substituir trabalho e trabalhadores, a maquinaria transformou-se imediatamente em meio de aumentar o número de assalariados, colocando todos os membros da família do trabalhador, sem distinção do sexo e idade, sob o domínio direto do capital.

No século XX, a criança começa a ser vista como cidadão, mas os pobres não estavam inseridos nesse modelo, elas eram tidas como membros que vagavam pelas ruas da cidade, vulneravam a marginalidade.

Nesse contexto em 1927 é criado o Código de Menores com decreto lei 17934 em 12 de outubro do referido ano, onde tinha 231 artigos , o qual não promovia ações educativas, era totalmente repressivo, onde julgava e protegia os filhos das camadas populares. Esse código via o trabalho infantil como ação educativa, pois as crianças pobres eram vistas como marginais.

A legislação de menores aprovada em 1927 reflete o protecionismo, um cuidado externo de garantir que a meta de salvar a criança fosse alcançada. Entendeu-se, porém, que isso seria feito através do exercício do mais absoluto controle pelo Estado sobre a população pobre, tido como promotora da desordem. Crianças e

\footnotetext{
${ }^{1}$ Utilizamos a discussão Questão Social legitimada pelo o Serviço Social que para (BEHRING e SANTOS, 2009) esse processo faz parte da estrutura da sociabilidade capitalista, que através da forma excludente da produção acaba desencadeando uma série de rebatimentos na sociedade fruto do conflito capital e trabalho.
} 
jovens eram minuciosamente classificados de acordo com ser estado de abandono e grau de periculosidade. (Padilha, 2006, p.42 e 43).

Esse Código de Menores não passava apenas de uma forma em que o Estado criou para dar respostas a classe burguesa, sobre a marginalidade das camadas populares, visando não uma proteção a essa população, mas sim uma forma de reprimi-los e manter a ordem, ou seja, manter o controle da sociedade. Portanto Rizzini descreve que:

De acordo com o Código, o menor não é apenas aquele individuo que tem idade inferior a 18 ou 21 anos, senão proveniente da família pobre, desorganizada, desestruturada, e que imperam os maus costumes, a prostituição, a vadiagem, a puçá instrução, o trabalho nas ruas para sobreviver, filho de pais que não ofereçam suficientes garantias de moralidade e capacidade econômica para educá-los. (Rizzini, 2008, p. 96)

Em 1941 tem-se o SAM (Serviço de Assistência ao Menor), onde se reconhece o problema do menor, tratado como uma expressão da questão social, vistos como carentes. De acordo com Miriam Padilha:

O SAM foi criado em 1941, pelo governo Getúlio Vargas, ligado então ao Ministério da Justiça e do Interior, e tinha como objetivo proporcionar, em todo território nacional, uma assistência social aos menores carentes e infratores da lei penal. A criação dessa instituição agregava uma perspectiva corretiva de natureza protecionista, prestando uma assistência psicopedagógica aos menores considerados carentes e delinqüentes. ( Padilha, 2006, p. 50)

Com a criação da LBA (Legião Brasileira da Assistência) em 1942, comandada pela primeira dama Darcy Vargas, têm-se a intervenção do Estado de forma assistencialista e caritativa nas ações voltadas as crianças.

Já em 1964 a FUNABEM (Fundação Nacional de Bem-Estar ao Menor), que tinha por objetivo a integração do menor e que depois transformou-se em FEBEM ( Fundação Estaduais do Menor). Segundo Miriam Padilha, “Com surgimento da FUNABEM teve-se uma Política Nacional de Bem-Estar do Menor, onde subordinou todas as entidades que prestavam atendimento as crianças e aos adolescentes." (Padilha, 2006, p. 50)

Porém as FEBEM não eram vistas como bons olhos, pois ela foi criada em um contexto histórico de Ditadura Militar, o qual visava controlar e manter a sociedade em perfeita harmonia, utilizando da violência e da repressão para que essa harmonização da sociedade fosse alcançada. Com isso, essas crianças e adolescentes em que eram enviadas para essas fundações, eram tratadas dessa forma, com a repressão e brutalidade. 
Contudo na década de 1980, com o fim da ditadura militar, período de agravamento das desigualdades sociais e democratização do país, nasce a Carta Magna, a Constituição Federal de 1988, a qual foi um marco na democracia do país, que em seu art. 227 vem preconizar a criança e o adolescente enquanto cidadão de direito, e em 13 de julho de 1990 criou-se o ECA (Estatuto da Criança e do Adolescente) o qual vem defender o social e jurídico em favor da criança e do adolescente. De acordo com Miriam Padilha:

\begin{abstract}
"O ECA foi aprovado em 13 de julho de 1990, que tinha o intuito de regulamentar esse direito constitucional de fundamentar essa política nacional de proteção à infância e a juventude no Brasil. Considerar a criança e o adolescente sujeitos de direitos significa assim, assegurar prioritariamente a efetivação de políticas públicas que estimule positivamente o seu desenvolvimento e os ponham a salvo de qualquer tratamento humano, violento, aterrorizante, vexatório ou constrangedor. Se não existirem políticas públicas, em quantidade e qualidade, a saúde, a educação, o lazer, a alimentação, não farão parte ou serão insuficientes para garantir o pleno desenvolvimento da criança e do adolescente, ou seja, eles estarão impossibilitados de exercer direitos de cidadania, perpetuando-se processo vicioso de exclusão em que as dificuldades socioeconômicas, o analfabetismo e a violência fazem do artigo 227 da CF de 88, um dispositivo implacável." (Padilha, 2006, p. 59 e 60)
\end{abstract}

O ECA tem a perspectiva de proteger, defender e viabilizar os direitos que são garantidos à todas as crianças e adolescentes desde 1988. Nesse estatuto indica que só é criança, quem possui até doze anos de idade incompletos e adolescentes entre doze e dezoito anos de idade incompletos. Em seu artigo $3^{\circ}$ é colocado que a criança tem que ter seu desenvolvimento saudável, tanto físico, moral, mental, espiritual e social, pois eles são considerados seres humanos com liberdade e dignidade.

Em seu art. 60 do Estatuto determina que a idade mínima para o trabalho é de 14 anos em condição de aprendiz, mas não é permitido trabalho noturno, perigoso e insalubre aos menores de 18 anos e nenhuma forma de trabalho para menores de 14.

O PETI (Programa de Erradicação do Trabalho Infantil) foi criado em 1996 pelo ente federal, que tem por objetivo erradicar todas as formas de trabalho de crianças e adolescentes menores de 16 anos de idade e dar condições mínimas para sua sobrevivência, salientando a saúde e a educação em que os menores têm o direito. O responsável por esse programa é o MDS (Ministério do Desenvolvimento e Combate a Fome). Segundo Minharro (2003, p. 94):

O Programa de Erradicação do Trabalho Infantil (PETI) é um projeto do governo federal, que tem por objetivo retirar crianças e adolescentes do trabalho perigoso, penoso, insalubre e degradante, bem como possibilitar-lhes o acesso, a permanência e o bom desempenho na escola. Pretende, também, fomentar e incentivar a participação desses jovens em atividades culturais, esportivas, artísticas e de lazer, aumentando a jornada escolar. No âmbito familiar, pretende implementar programas e projetos de geração de trabalho e renda para famílias. 
Os pais das crianças inseridas nesse programa recebem também o PBF (Programa Bolsa Família), onde esses dois programas só vincularam-se em 2003. O PETI acaba fazendo parte do programa de renda mínima, para as famílias que sejam vulneráveis, com renda per capita até meio salário mínimo e com filhos de 7 a 14 anos de idade, submetidos ao trabalho, onde o mesmo funciona tanto na zona urbana como na zorra rural.

"O PETI contempla o pressuposto da Política de Assistência Social, por atender temporariamente aos beneficiários que vivem em situação de vulnerabilidade." (Padilha, 2006 p. 81)

Contudo, o PETI é um excelente programa para erradicar o trabalho infantil, porém por o mesmo ser seletivo, temporário e focalista, que é viabilizado somente pelas pessoas consideradas "pobres"2, ele não possui tanta eficiência, sendo necessária ampliação do mesmo, em que ele possa comportar todas famílias de que vivem nessa situação.

Porém ainda na atualidade obtém crianças no interior do trabalho informal, onde os mesmos são explorados e com uma mão de obra barata, pois infelizmente algumas pessoas vem esse questão como um meio de educar crianças e adolescentes para a vida, não tendo a noção do quão prejudicial é para a infância.

\section{Suas causas e consequências}

Percebe-se que o trabalho infantil é uma problemática que ainda persiste em nossa sociedade, desfrutando do labor da criança e do adolescente de forma imprópria e que trazem consequiências na vida dos mesmos desastrosas, podendo levá-los até a morte.

Pois para a concepção de Alberto:

"O trabalho precoce é uma forma de violação de direitos humanos, uma vez que agride os direitos universais, o direito à vida, à integridade, física, e a dignidade de pessoa humana.(Alberto, 2007, p.24)

Os dados do PNAD, na atualidade afirma que ainda existem cerca de 4,8 milhões de crianças e adolescentes entre 5 e 17 anos de idade trabalhando no Brasil, porém desse total 1,2 milhões estão na faixa etária de 5 e 13 anos de idade, segundo PNAD 2007.

A principal causa em que leva uma criança e adolescente ao trabalho é a pobreza, pois a mesma é o fator condicionante para que essa expressão da questão social permaneça em nossa sociedade, pois as famílias que vivem nessa situação buscam manter todos os filhos no trabalho, onde é a única forma de garantir alguma renda mensal e consequentemente a sobrevivência da família.

\footnotetext{
${ }^{2}$ Ou seja, perfil socioeconômico inferior a ${ }^{1 / 4}$ de um salário mínimo, preconizado pela política de assistência.
} 
Porém outros fatores contribuem para esse problema, como o desemprego crescente, já que a mão-de-obra infantil é mais barata do que a mão-de-obra adulta, colocando o fácil acesso de crianças no meio do trabalho pois existem empregadores corruptos, outro fator é má condição das escolas, onde as escolas públicas oferecem péssimas condições escolar para a sociedade, a locomoção de muitas crianças e adolescentes também é de extrema dificuldade para chegar ao meio escolar, fazendo com que os mesmos desistam dos estudos e busquem lugares como o meio do trabalho.

É visto que o trabalho precoce prejudica o individuo, pois interfere no seu desenvolvimento físico, psíquico, educacional, moral, e social. Muitas são as consequiência dessa questão, porém é notável que as crianças e adolescentes estejam em fase de desenvolvimento físico, mental, motor e o trabalho pode ocasionar acidentes graves, podendo levá-los até a morte.

Segundo Alberto:

\begin{abstract}
"O Combate do trabalho precoce constitui uma temática e um problema que preocupam a sociedade brasileira. A prática do trabalho precoce não é uma coisa recente, mas persiste mesmo ante denúncias e políticas públicas em diferentes níveis nacional e internacional. Infelizmente, ainda, convivemos em uma sociedade que concorda e incentiva crianças a trabalharem acreditando que assim esta livrando-as da marginalidade das ruas." (Alberto, 2007, p.81)
\end{abstract}

$\mathrm{Na}$ atualidade possuem debates acerca do trabalho infantil sobre a violação dos direitos humanos, pois os mesmos são submetidos a exploração, abuso, violação ao seu direito de desenvolvimento.

A evasão escolar na atualidade ainda é muito crescente, pois quando uma criança é inserida precocemente no mercado de trabalho, a mesma não realiza atividades referentes a sua idade, como brincar, estudar, buscar uma socialização com pessoas da mesma faixa etária, onde todas essas questões são de suma importância para sua formação enquanto ser humano.

Para tanto a maior conseqüência é a falta da educação da criança, já que longe dos estudos, as mesmas não possuem conhecimento, acabando então por repetir a vida de seus pais, tornando-se adultos despreparados para o mercado de trabalho, fazendo com que numa acabe o ciclo da pobreza.

\title{
2. O papel da família nessa expressão da questão social
}

Um dos grandes fatores em que influenciam ao trabalho infantil, é a questão da pobreza familiar, ou seja, a baixa renda familiar, onde a criança se vê obrigada a ajudar, ou até mesmo manter o sustento da casa, é essa umas das estratégias em que os pais criam para poder sobreviver.

Id en line Revista de Psicologia. Ano 7, No. 21, Novembroo/2013 - ISSN 1981-1179

Edição eletrônica em http://idonline.emnuvens.com.br/id 
O seio familiar é a base em que a criança e o adolescente vão se definir e formar a sua personalidade, por meio da qual é busca-se ser a fonte de fortificação para esses indivíduos, onde Mota coloca que:

[...] analisa a família como instituição social contraditória e conflitiva, na qual ao mesmo tempo em que se reproduzem as relações sociais, torna-se possivel instituir espaço para a construção de valores e idéias que permitem a formação e constituição de uma sociabilidade, possibilitando ao grupo familiar criar padrões de comportamento e cultura.( MOTA, 2010 p. 206)

O Programa de Erradicação do Trabalho Infantil (PETI) é um programa em que visa excluir tão problemática do nosso país, com vistas principalmente em trabalhar não só a criança e o adolescente mais principalmente as famílias, pois o foco é fortalecer os vínculos familiares, juntamente com outras políticas públicas, como a educação, a saúde, habitação.

É de suma importância a composição e estruturação familiar, pois isso implica no trabalho infantil. Com isso, percebe-se que a desestruturação da família tem uma grande relação com a pobreza, e consequentemente com a exploração do trabalho de crianças e adolescentes. Como Oliveira e Pires ( 1995, p. 253-254):

\begin{abstract}
A desestruturação do núcleo familiar, sobretudo com a ausência do pai, é fator que impulsiona a entrada precoce no mercado de trabalho porque, nesta hipótese, o trabalho infanto-juvenil torna-se mais crucial para a renda familiar. O desemprego dos pais ou a inatividade dos mesmo por motivo de doença são outros fatores que imediatamente acentuam a utilização do trabalho infantil.
\end{abstract}

Ou seja, a família tem um foco principal nessa expressão da questão social, pois a mesma é quem deve dar o suporte necessário para que a criança e o adolescente tenham uma vida favorável, saudável, de socialização com outros indivíduos, para mais adiante ser uma adulto satisfeito e prospero.

A unidade familiar é o foco centralizador da atenção do PETI, ainda que sua finalidade última seja erradicar o trabalho infantil como uma problemática que afeta aos direitos humanos a expressão das péssimas condições de vida em qe vive grande parte da população. (MOTA, 2010 p. 216)

Em especial o seio familiar tem que incentivar a educação, porém tudo isso poderia acontecer se as políticas públicas tivessem qualidade, e fossem efetivadas como deveriam, mas ao contrário as mesmas vivem na carência, e isso dificulta a vida dessas famílias precisam das mesmas. 


\section{Considerações Finais}

Sabe-se que a exploração do trabalho infantil é uma expressão da questão social que é (re)produzida no decorrer dos tempos, é com a Revolução Industrial que esse fenômeno se acentua, no entanto vai ter uma maior preocupação com tal problemática. Porém, muito tempo depois, essa realidade ainda permanece, pois esse "problema social" está inserido no modo de produção capitalista e é utilizado como meio para ampliar a produção e reprodução do capital, é um processo inerente aos ditames do modelo de produção vigente.

No que se diz respeitos aos direitos e as formas de proteção viu-se que a criança e o adolescente era tratado como marginal, delinqüente e tinha uma proteção do Estado de forma punitiva e coercitiva, com o passar dos tempos, a criança ela passa a ser considerada cidadã, e começa a ser inserida nas políticas públicas (como o centro da questão), porém a mesma não torna-se suficiente para erradicar o trabalho infantil, pois a pobreza é uma das principais causas em que esses indivíduos sejam inseridos de maneira imprópria ao trabalho, porque sua mão de obra é barata, moldável no qual ajuda a ampliação do capitalismo.

Mas, é conveniente que essa expressão da questão social seja erradicada, pois as suas conseqüências para a criança e o adolescente é trágico, onde prejudica sua saúde, o seu desenvolvimento físico, social, educacional, psicológico e moral.

Porém existe várias formas de enfrentamento desse problema, que vai desde das legislações até as políticas sociais, como exemplo o PETI, ligado a política de assistência social, que é de forma descontinua, focalista, temporária, o qual não erradica o problema pela raiz, o mesmo só sobrepõe uma amenização. Conclui-se que na legislação é que trabalho para menores de 16 anos de idade é crime, visto somente em condição de aprendiz a partir dos 14 anos de idade, sem ser a condicionado a trabalho noturno, insalubre, ou que o mesmo corra risco de vida.

Percebe-se então, que o trabalho infantil é uma forma de negação da infância, comprometendo mais adiante o futuro do cidadão.

No entanto, é necessário que haja realmente o processo de participação da sociedade junto ao governo para pressionar o mesmo, estruturarão das políticas sociais públicas e fazer com que as políticas sociais sejam mais eficazes, onde devem gerar mais emprego de qualidade, melhorar a educação do país, defender e efetivar os direitos que estão na lei, ampliar e efetivar de forma eficaz as políticas públicas, implementar não só ações preventivas, ou paliativas para tirar milhares de crianças e adolescente neste mundo do trabalho, mas sim, implementar ações, estratégias e programas que erradique de vez tal problemática, fazendo com que esses cidadãos sejam sujeitos em que saia desse

Id en line Revista de Psicologia. Ano 7, No. 21, Novembroo/2013 - ISSN 1981-1179

Edição eletrônica em http://idonline.emnuvens.com.br/id 
ciclo de pobreza, que tenha uma educação eficiente para poder assim ter um emprego na sua vida adulta em que busque uma melhor qualidade de vida, mesmo sabendo que isso é um grande desafio

\section{Referências:}

ALBERTO, Maria de Fátima Pereira. Crianças e adolescentes trabalhando? Uma estratégia de sobrevivência que atravessa gerações. João Pessoa: editora universitária- UFPB, 2007.

BEHRING, Elaine R. e SANTOS, Silvana M. de Moraes. Questão Social e direitos. In: CFESS. Serviço social: direitos sociais e competências profissionais. Brasília: CEFESS/ABEPSS, 2009.

MARX, Karl. O Capital: a crítica a economia política. Livro I, v. I e II. Rio de Janeiro: Civilização Brasileira, 1968.

MINHARRO, Eroltide Ribeiro dos Santos. A Criança e o Adolescente no Direito do Trabalho. São Paulo: LTr, 2003.

OLIVEIRA, O. de; Pires, J.M. O trabalho da criança e do adolescente. In: FERNANDES, R. (1995). O trabalho no Brasil no limiar do século XXI. São Paulo: LTr, 1995.

PADILHA, Miriam Damasceno. Assistência Social, Trabalho Infantil e família. In: MOTA, Ana Elizabete, (Org.) O Mito da Assistência Social: ensaios sobre Estado, Política e Sociedade. 4.ed. São Paulo: Cortez, 2010.

PADILHA, Miriam Damasceno. Criança não deve trabalhar: análise sobre o Programa de Erradicação do Trabalho Infantil e a repercussão na sociabilidade familiar. Recife. CEPE, 2006.

RIZZINI, Irene. O século Perdido: raízes históricas das políticas públicas para a infância no Brasil. 2.ed. São Paulo: Cortez, 2008.

\section{Como citar este artigo (Formato ISO):}

ALVES, C.C.R.;SOUZA, L.A.; CLEMENTINO, V.E.V.; FERREIRA, J.G.. Trabalho infantil: uma discussão sobre direitos, causas e consequências. Id on Line Revista de Psicologia, Novembro de 2013, vol.1, n.21, p. 54-63. ISSN 1981-1189. 